Daniel T.L. Shek*, Jianqiang Liang and Moon Y.M. Law

\title{
Subjective outcome evaluation of a university subject on leadership and intrapersonal development
}

DOI 10.1515/ijdhd-2016-0714

Received September 18, 2014; accepted October 13, 2014; previously published online May 28, 2016

\begin{abstract}
First-year undergraduate students $(\mathrm{n}=890)$ responded to a 48-item subjective outcome evaluation scale (SOES) after taking a leadership subject at The Hong Kong Polytechnic University in the second semester of the 2012-2013 academic year. Consistent with our expectation, factor analyses showed that the scale contains three dimensions (program, instructor and benefits). Results showed that students had positive perceptions of the program contents and the instructors, and most of the students perceived the subject to be beneficial to their development in different areas. As predicted, perceived qualities of the program and instructors were significant predictors of the perceived effectiveness of the program. Perceived qualities of the program, instructors and benefits predicted student's overall satisfaction with the program.
\end{abstract}

Keywords: factor analysis; holistic development; leadership; multiple regression; subjective outcome evaluation; university students.

\section{Introduction}

University is an important place for the social and psychological transitions from adolescence to adulthood.

*Corresponding author: Professor Daniel T.L. Shek, PhD, FHKPS, BBS, SBS, JP, Associate Vice President and Chair Professor of Applied Social Sciences, Department of Applied Social Sciences, Faculty of Health and Social Sciences, The Hong Kong Polytechnic University, Room HJ407, Core H, Hunghom, Hong Kong, P.R. China, E-mail: daniel.shek@polyu.edu.hk; Centre for Innovative Programmes for Adolescents and Families, The Hong Kong Polytechnic University, Hong Kong, P.R. China; Department of Social Work, East China Normal University, Shanghai, P.R. China; Kiang Wu Nursing College of Macau, Macau, P.R. China; and Division of Adolescent Medicine, Department of Pediatrics, Kentucky Children's Hospital, University of Kentucky College of Medicine, Lexington, KY, USA

Jianqiang Liang and Moon Y.M. Law: Department of Applied Social Sciences, The Hong Kong Polytechnic University, Hong Kong, P.R. China
Freshmen are usually given opportunities to develop their personal, academic and career interests in a self-regulated learning environment. However, recent studies on college students showed that they are facing challenges in intrapersonal and interpersonal development, such as substance abuse, Internet addition, inappropriate sexual behavior, lack of a purposeful life, lack of civic and community engagement [1-3]. They also have a high risk of having mental health issues, such as depression, anxiety and suicidality [4]. These developmental issues could have negative influences on both their academic performance and healthy transitions to adulthood. For educators, it is becoming urgent to integrate the university curriculum with educational programs to promote student's intrapersonal and interpersonal development $[5,6]$.

Developmentally speaking, university freshmen go through multiple life transitions - from adolescent to young adult; from dependence to independence from parents; from being disciplined to becoming self-disciplined and responsive to the societal demands. In fact, they have more interactions with people from different backgrounds. They are experiencing transformations as well - such as forming a new identity, taking different roles, and developing intrapersonal and interpersonal competencies. What they need is not only "solution" for academic performance, but more importantly, "space" and "support" for the holistic development in all domains. To respond to this challenge, many scholars argued for promoting inner strengths of university students $[7,8]$. The inner strengths (e.g. competence, resilience, aspiration) are important for university students not only because they help promote their psychosocial wellbeing, but also they protect them from the development of risk behavior.

To promote holistic development of university students, Shek [5] developed a leadership subject entitled “Tomorrow's Leaders" which attempts to promote leadership and intrapersonal competencies for university students at The Hong Kong Polytechnic University. After successfully running as a pilot project in the 2010-2012 academic years [6,9], the program was officially offered as a credit-bearing subject to more than 2100 freshmen per year. The course content includes teaching and learning 
the personal attributes of becoming a whole person and an effective leader which covers self-understanding, emotional competence, cognitive competence, social competence, resilience, morality, spirituality and team building. The course is taught by a team of lecturers and tutors, who pair up for each class. In order to maintain consistency of teaching input and learning output, the team meets twice a month to discuss the progress of teaching, students' feedback and ways to promote the teaching and learning quality.

The subjective outcome evaluation scale (SOES) was developed [6] which attempted to measure the students' perception of the program outcomes and the effectiveness of the program on their holistic development. Results from the initial studies $[9,10]$ showed that the students were satisfied with the qualities of the subject and the instructors and that the subject was conducive to promoting their intrapersonal and interpersonal development. This paper aims to further examine the psychometric properties of the scale and investigate the students' satisfaction as well as program effectiveness (PE) of the course using a new set of data collected from different student cohorts.

With reference to the focus of the paper, there is obviously the question on why post-course subjective outcome evaluation was used. From a post-positivistic research point of view, both objective outcome and subjective outcome evaluation are important. While the former measures psychosocial functioning of the program participants, the latter assesses the program participants' perceptions of the program outcomes and benefits to their personal development [11]. Subjective outcome evaluation has been used to promote practice evaluation in the field of education, including the classroom teaching and learning. It helps researchers understand the students' overall satisfaction through their perceptions of the program content, quality of facilitation and benefits of the program. In this study, the SOES can help to examine the effectiveness of "Tomorrow's Leaders" on the improvement of intrapersonal and inner strengths of university students, such as attributes of critical thinking, problem solving, life-long learning, effective communication and ethical leadership. Several research questions were addressed in this study as follows:

1. What are the psychometric properties of the SOES? With reference to previous research, it was expected that three dimensions could be extracted from the scale.

2. What are the perceptions of the students on the subject, instructors and benefits of the subject?

3. What are the inter-relationships between perceived program quality (PQ), instructors and benefits? Based on previous studies $[9,10]$, it was hypothesized that the three major aspects of subjective outcomes (i.e. $\mathrm{PQ}$, instructor quality and $\mathrm{PE}$ ) would be inter-related (Hypotheses 1a, 1b and 1c).

- Hypothesis 1a: PQ and instructor quality would be inter-related.

- Hypothesis 1b: PQ and PE would be inter-related.

- Hypothesis 1c: Instructor quality and PE would be inter-related.

4. Do perceived program and instructor qualities predict perceived benefits of the subject? Based on past studies [9, 10], students' perceived program and instructor qualities would predict their perceived benefits of the subject (Hypotheses 2a and 2b).

- Hypothesis 2a: PQ would predict PE.

- Hypothesis $2 \mathrm{~b}$ : Instructor quality would predict PE.

5. What is the impact of perceived subject, instructors and benefits on students' overall satisfaction with the subject? Based on previous research findings [9, 10], it was hypothesized that these three aspects of subjective outcome evaluation would predict students' overall satisfaction with the subject (Hypothesis 3).

- Hypothesis 3: PQ, instructor quality and PE would predict overall satisfaction with the subject.

\section{Methods}

The participants $(\mathrm{n}=890)$ were those who took "Tomorrow's Leaders" in semester two of the 2012-2013 academic year. They were invited to respond to the study voluntarily. The participants filled in the questionnaire in a self-administration format. Enough time was given to each student to complete the questionnaire. The collected questionnaires were scanned by a reliable machine called "Datacap" with a well-designed statistics software entitled "Toptest". All the data were cleaned by well-trained research assistants.

\section{Instruments}

A modified SOES was used in the evaluation which was validated in the previous study [6]. Factor analyses showed that there were three dimensions intrinsic to the scale, including perceived quality of the program, perceived quality of instructors (QI) and perceived benefits of the subject. Reliability analyses also showed that the total scale and the three subscales had adequate reliability. There are several parts of the closed questions:

1. PQ includes eight items (a1, a2, a3, a4, a5, a6, a7, a8 in Table 1).

2. QI includes 10 items (b1, b2, b3, b4, b5, b6, b7, b8, b9, b10 in Table 2).

3. PE includes 21 items (c1, c2, c3, c4, c5, c6, c7, c8, c9, c10, c11, c12, c13, c14, c15, c16, c17, c18, c19, c20, c21 in Table 3).

4. Overall satisfaction with the program, includes three items (a9, a10, e1) with a six-point Likert-type scale. 
Table 1: Summary of the participants' perceptions towards the program (PQ).

\begin{tabular}{|c|c|c|c|c|c|c|c|c|c|c|c|c|c|c|}
\hline & \multicolumn{2}{|r|}{1} & \multicolumn{2}{|r|}{2} & \multicolumn{2}{|r|}{3} & \multicolumn{2}{|r|}{4} & \multicolumn{2}{|r|}{5} & \multicolumn{2}{|r|}{6} & \multicolumn{2}{|c|}{ Positive } \\
\hline & $\mathbf{n}$ & $\%$ & $\mathbf{n}$ & $\%$ & $\mathbf{n}$ & $\%$ & $\mathbf{n}$ & $\%$ & $\mathbf{n}$ & $\%$ & $\mathbf{n}$ & $\%$ & $\mathrm{n}$ & $\%$ \\
\hline a1. Objectives of the curriculum are very clear & 5 & 0.60 & 7 & 0.80 & 33 & 3.70 & 243 & 27.30 & 534 & 60.10 & 67 & 7.50 & 844 & 94.80 \\
\hline a2. Design of the curriculum is very good & 8 & 0.90 & 10 & 1.10 & 52 & 5.80 & 288 & 32.40 & 461 & 51.90 & 70 & 7.90 & 819 & 92.02 \\
\hline a3. Activities were carefully arranged & 3 & 0.30 & 5 & 0.60 & 24 & 2.70 & 246 & 27.60 & 523 & 58.80 & 89 & 10.00 & 858 & 96.40 \\
\hline a4. Classroom atmosphere was very pleasant & 3 & 0.30 & 6 & 0.70 & 48 & 5.40 & 267 & 30.10 & 455 & 51.20 & 109 & 12.30 & 831 & 93.37 \\
\hline a5. Peer interaction amongst the students & 3 & 0.30 & 7 & 0.80 & 31 & 3.50 & 242 & 27.30 & 454 & 51.20 & 150 & 16.90 & 846 & 95.06 \\
\hline a6. I participated actively during lessons & 5 & 0.60 & 15 & 1.70 & 58 & 6.50 & 277 & 31.20 & 439 & 49.40 & 95 & 10.70 & 811 & 91.12 \\
\hline a7. I was encouraged to do my best & 3 & 0.30 & 5 & 0.60 & 44 & 5.00 & 308 & 34.70 & 445 & 50.10 & 83 & 9.30 & 836 & 93.93 \\
\hline a8. Enhanced my interest towards the lessons & 13 & 1.50 & 27 & 3.00 & 87 & 9.80 & 326 & 36.70 & 381 & 42.90 & 55 & 6.20 & 762 & 85.62 \\
\hline
\end{tabular}

All items are on a six-point Likert scale with $1=$ strongly disagree, $2=$ disagree, $3=$ slightly disagree, $4=$ slightly agree, $5=$ agree, $6=$ strongly agree. Positive $=$ Participants with positive responses (options 4-6).

Table 2: Summary of the participants' perceptions towards the implementers (QI).

\begin{tabular}{|c|c|c|c|c|c|c|c|c|c|c|c|c|c|c|}
\hline & & 1 & & 2 & & 3 & & 4 & & 5 & & 6 & & ositive \\
\hline & n & $\%$ & $\mathrm{n}$ & $\%$ & $\mathbf{n}$ & $\%$ & $\mathbf{n}$ & $\%$ & $\mathbf{n}$ & $\%$ & $\mathbf{n}$ & $\%$ & $\mathbf{n}$ & $\%$ \\
\hline b1. The lecturer(s) had a good mastery of the curriculum & 2 & 0.20 & 1 & 0.10 & 12 & 1.30 & 179 & 20.10 & 497 & 55.90 & 198 & 22.30 & 874 & 98.20 \\
\hline b2. The lecturer(s) was (were) well prepared for the classes & 2 & 0.20 & 0 & 0 & 12 & 1.30 & 122 & 13.70 & 468 & 52.60 & 285 & 32.10 & 875 & 98.31 \\
\hline b3. The teaching skills of the lecturer(s) were good & 3 & 0.30 & 2 & 0.20 & 21 & 2.40 & 174 & 19.60 & 484 & 54.40 & 206 & 23.10 & 864 & 97.08 \\
\hline b4. The lecturer(s) showed good professional attitudes & 3 & 0.30 & 3 & 0.30 & 18 & 2.00 & 133 & 15.00 & 457 & 51.50 & 274 & 30.90 & 864 & 97.08 \\
\hline b5. The lecturer(s) was (were) very involved & 2 & 0.20 & 1 & 0.10 & 11 & 1.20 & 116 & 13.00 & 461 & 51.90 & 298 & 33.50 & 875 & 98.31 \\
\hline b6. The lecturer(s) encouraged students to participate & 2 & 0.20 & 1 & 0.10 & 8 & 0.90 & 138 & 15.50 & 476 & 53.60 & 263 & 29.60 & 877 & 98.54 \\
\hline b7. The lecturer(s) cared for the students & 2 & 0.20 & 5 & 0.60 & 14 & 1.60 & 184 & 20.70 & 442 & 49.80 & 241 & 27.10 & 867 & 97.42 \\
\hline b8. The lecturer(s) was (were) ready to offer help & 2 & 0.20 & 3 & 0.30 & 11 & 1.20 & 137 & 15.40 & 478 & 53.80 & 257 & 28.90 & 872 & 97.98 \\
\hline b9. The lecturer(s) had much interaction with the students & 2 & 0.20 & 3 & 0.30 & 17 & 1.90 & 200 & 22.50 & 481 & 54.10 & 186 & 20.90 & 867 & 97.42 \\
\hline b10. I have very positive evaluation of the lecturer(s) & 6 & 0.70 & 1 & 0.10 & 19 & 2.10 & 122 & 13.70 & 492 & 55.30 & 249 & 28.00 & 863 & 96.97 \\
\hline
\end{tabular}

All items are on a six-point Likert scale with $1=$ strongly disagree, 2 =disagree, $3=$ slightly disagree, $4=$ slightly agree, $5=$ agree, $6=$ strongly agree. Positive $=$ Participants with positive responses (options 4-6).

5. The extent to which the students would recommend the course to their friends (d1) and the extent to which the students would join similar courses in the future (d2) with a six-point Likert-type scale.

6. There are four open-ended questions to explore further the learning experience from the students, including: (a) The important things that the students learned from the course; (b) Things that the students appreciated most; (c) Comments about the instructor and tutor; and (d) Areas for the course to improve.

However, only quantitative data based on the rating scale items were examined in this study.

\section{Data analyses}

All data analyses were performed by SPSS 21 (IBM SPSS Statistics, IBM Corp, Somers, NY). Descriptive statistics (frequencies and percentage values) were calculated. A composite measure of each sub-scale (i.e. perceptions of program, perceptions of instructors, perceived PE, and overall effectiveness) was created based on the total scores of each scale divided by the number of items. Pearson correlation analyses were performed to investigate whether
$\mathrm{PQ}$ and instructor quality were related to the PE (Hypotheses 1a to 1c). Multiple regression analyses were conducted to examine how well each factor would predict PE (Hypotheses $2 \mathrm{a}$ and $2 \mathrm{~b}$ ) and to explore the predictors of overall satisfaction with the subject (Hypothesis 3).

\section{Results}

\section{Research question 1: psychometric properties of the SOES}

Correlation matrix showed that inter-item correlation coefficients of the 39 items (total items of $\mathrm{PQ}, \mathrm{QI}$ and $\mathrm{PE}$ ) were all above 0.30. In this sample, KMO value was 0.982 , and the Bartlett's test was significant $(\mathrm{p}<0.0001)$, which suggested that factor analysis was appropriate for this sample. Principal factor analysis showed that three factors were extracted from the scale with eigenvalues above 1 (eigenvalue $=21.192$, 4.111, 1.359), accounting for $68.36 \%$ of the 


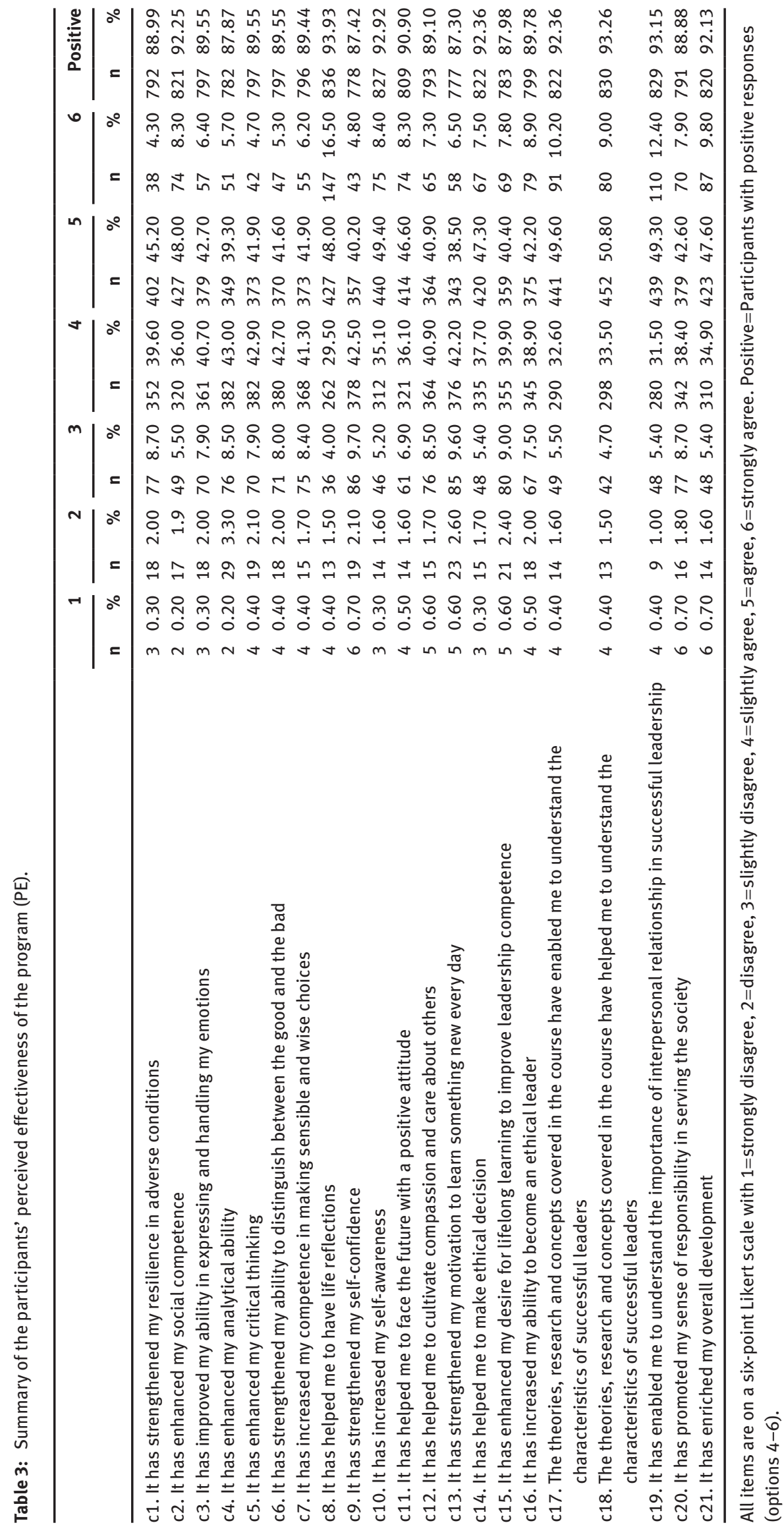


Table 4: Rotated factor structure of SOES.

\begin{tabular}{|c|c|c|c|}
\hline \multirow[t]{2}{*}{ Items } & \multicolumn{3}{|c|}{ Component } \\
\hline & 1 (PE) & $2(Q I)$ & $3(P Q)$ \\
\hline a1 & & & 0.606 \\
\hline a2 & & & 0.631 \\
\hline a3 & & & 0.679 \\
\hline $\mathrm{a} 4$ & & & 0.643 \\
\hline a5 & & & 0.662 \\
\hline a6 & & & 0.645 \\
\hline a7 & & & 0.571 \\
\hline a8 & & & 0.559 \\
\hline b1 & & 0.710 & \\
\hline b2 & & 0.795 & \\
\hline b3 & & 0.755 & \\
\hline b4 & & 0.804 & \\
\hline b5 & & 0.801 & \\
\hline b6 & & 0.788 & \\
\hline b7 & & 0.786 & \\
\hline b8 & & 0.807 & \\
\hline b9 & & 0.737 & \\
\hline b10 & & 0.810 & \\
\hline c1 & 0.727 & & \\
\hline c2 & 0.676 & & \\
\hline$c 3$ & 0.761 & & \\
\hline$c 4$ & 0.763 & & \\
\hline c5 & 0.820 & & \\
\hline$c 6$ & 0.808 & & \\
\hline c7 & 0.803 & & \\
\hline$c 8$ & 0.685 & & \\
\hline c9 & 0.777 & & \\
\hline c10 & 0.743 & & \\
\hline c11 & 0.789 & & \\
\hline c12 & 0.792 & & \\
\hline c13 & 0.796 & & \\
\hline c14 & 0.783 & & \\
\hline c15 & 0.754 & & \\
\hline c16 & 0.794 & & \\
\hline c17 & 0.685 & & \\
\hline c18 & 0.672 & & \\
\hline c19 & 0.688 & & \\
\hline c20 & 0.767 & & \\
\hline c21 & 0.804 & & \\
\hline
\end{tabular}

Extraction method: principal component analysis. Rotation method: varimax with Kaiser normalization. a. Rotation converged in five interactions. a1-a8: items on perceived program qualities. b1-b10: items on perceived instructor qualities. $11-c 21$ : items on perceived benefits. PE, Program effectiveness; $\mathrm{QI}$, quality of instructor; $\mathrm{PQ}$, program quality.

variance. The first factor (PE) explained $54.34 \%$ of the total variance; second factor (QI) explained $10.54 \%$ of the total variance; third factor $(\mathrm{PQ})$ explained $3.49 \%$ of the total variance. Table 4 shows the rotated factor structure of the scale.

In Table 5, reliability analyses showed that SOES was internally consistent: eight items related to the program
( $\alpha=0.92), 10$ items related to the implementer ( $\alpha=0.95$ ), 21 items related to the benefits $(\alpha=0.98)$, the total 39 items measuring PE $(\alpha=0.98)$, and the three items assessed overall satisfaction of students on this program $(\alpha=0.88)$.

\section{Research question 2: students' satisfaction with the subject, instructors and benefits}

From Tables 1-3, 6, 7 results showed that most of the students were satisfied with the subject, instructors and benefits. In terms of PQ, 94.8\% agreed that the objective of the curriculum was very clear, $96.4 \%$ appreciated the welldesigned activities, and $95.1 \%$ enjoyed the peer interaction among students. In terms of QI, 98.31\% thought that the lecturer and tutor were very involved, 98.54\% thought that they were encouraged by the lecturer and tutor. In terms of PE, 93.93\% agreed that the course helped them with life reflections, 92.92\% agreed that it strengthened their self-awareness, $93.26 \%$ thought that the theories, research and concepts covered in the course had enabled them to understand the characteristics of a successful leader, $92.13 \%$ thought that it was effective at promoting holistic development.

Besides, $77.30 \%$ of the students would recommend this course to their friends, suggesting that many of them were satisfied with what they had learnt from "Tomorrow's Leaders", and they wanted to share the information with their friends. In addition, 55.28\% of the students would consider taking similar courses, with many students were looking forward to join an advanced level leadership course (i.e. "Service Learning”, "Service Leadership") to apply the theories and knowledge of leadership and holistic personal development through practices in the community.

\section{Research question 3: inter-relationships amongst different aspects of SEOS}

Table 8 shows that PQ and QI were strongly related $(\mathrm{r}=0.70 ; \mathrm{p}<0.01)$. Total effectiveness was strongly related with PQ $(r=0.89 ; \mathrm{p}<0.01)$, QI $(\mathrm{r}=0.77 ; \mathrm{p}<0.01)$ and PE $(r=0.95 ; p<0.01)$. These findings gave support to Hypotheses 1a to $1 c$.

\section{Research question 4: prediction of perceived benefits by perceived program and instructor qualities}

Table 8 also shows that both PQ $(r=0.76 ; p<0.01)$ and QI $(\mathrm{r}=0.55 ; \mathrm{p}<0.01)$ were both strongly associated with 
Table 5: Means, standard deviations, Cronbach's $\alpha$, and means of inter-item correlations of each subscale.

\begin{tabular}{lcccc}
\hline & Mean & SD & Cronbach's $\boldsymbol{\alpha}$ & $\begin{array}{r}\text { Mean inter-item } \\
\text { correlations }\end{array}$ \\
\hline 1. Program quality (PQ: 8 items) & 4.63 & 0.66 & 0.92 & 0.60 \\
2. Quality of instructor (QI: 10 items) & 5.06 & 0.63 & 0.95 & 0.67 \\
3. Program effectiveness (PE: 21 items) & 4.49 & 0.69 & 0.98 & 0.66 \\
4. Total effectiveness (39 items) & 4.68 & 0.59 & 0.98 & 0.51 \\
5. Overall satisfaction (3 items) & 4.46 & 0.84 & 0.88 & 0.71 \\
\hline
\end{tabular}

Table 6: Summary of the participants' perceptions towards the program.

\begin{tabular}{|c|c|c|c|c|c|c|c|c|c|c|c|c|c|c|}
\hline & & 1 & & 2 & & 3 & & 4 & & 5 & & 6 & & ositive \\
\hline & $n$ & $\%$ & $n$ & $\%$ & $\mathbf{n}$ & $\%$ & $\mathbf{n}$ & $\%$ & $n$ & $\%$ & $\mathbf{n}$ & $\%$ & $\mathbf{n}$ & $\%$ \\
\hline a9. I have very positive evaluation of the program & 5 & 0.60 & 21 & 2.40 & 54 & 6.10 & 267 & 30.30 & 445 & 50.50 & 90 & 10.20 & 802 & 90.11 \\
\hline a10. I like this curriculum very much & 11 & 1.30 & 39 & 4.7 & 70 & 8.40 & 302 & 36.10 & 353 & 42.20 & 61 & 7.30 & 716 & 80.45 \\
\hline e1. Overall, are you satisfied with this course? & 10 & 1.10 & 23 & 2.60 & 44 & 5.00 & 409 & 46.10 & 310 & 34.90 & 92 & 10.40 & 811 & 91.12 \\
\hline
\end{tabular}

All items are on a six-point Likert scale with $1=$ strongly disagree, $2=$ disagree, $3=$ slightly disagree, $4=$ slightly agree, $5=$ agree, $6=$ strongly agree. Item 3 (i.e. e1) is on a six-point Likert scale with $1=$ very dissatisfied, $2=$ moderately dissatisfied, $3=$ dissatisfied, $4=$ satisfied, $5=$ moderately satisfied, $6=$ very satisfied. Positive=Participants with positive responses (options 4-6).

Table 7: Other aspects of subjective outcome evaluation.

\begin{tabular}{|c|c|c|c|c|c|c|c|c|c|}
\hline & \multirow[b]{2}{*}{1} & & \multirow[b]{2}{*}{2} & & \multirow[b]{2}{*}{3} & \multicolumn{4}{|c|}{ d1. Will you suggest your friends to take this course? } \\
\hline & & & & & & \multicolumn{2}{|r|}{4} & \multicolumn{2}{|r|}{ Positive } \\
\hline \multicolumn{2}{|c|}{$\begin{array}{r}\text { Definitely will not } \\
\text { suggest }\end{array}$} & \multicolumn{2}{|c|}{ Will not suggest } & \multicolumn{2}{|c|}{ Will suggest } & \multicolumn{2}{|c|}{$\begin{array}{r}\text { Definitely will } \\
\text { suggest }\end{array}$} & \multicolumn{2}{|c|}{$\begin{array}{r}\text { Participants with } \\
\text { positive responses } \\
\text { (options } 3-4)\end{array}$} \\
\hline $\mathbf{n}$ & $\%$ & $\mathbf{n}$ & $\%$ & $\mathbf{n}$ & $\%$ & $\mathbf{n}$ & $\%$ & n & $\%$ \\
\hline \multirow[t]{3}{*}{47} & 5.30 & 151 & 17.00 & 546 & 61.60 & 142 & 16.00 & 688 & 77.30 \\
\hline & & & & & \multicolumn{5}{|c|}{ d2. Will you participate in similar courses again in the future? } \\
\hline & 1 & & 2 & & 3 & & 4 & & Positive \\
\hline \multicolumn{2}{|c|}{$\begin{array}{r}\text { Definitely will not } \\
\text { participate }\end{array}$} & \multicolumn{2}{|c|}{ Will not participate } & \multicolumn{2}{|c|}{ Will participate } & \multicolumn{2}{|c|}{$\begin{array}{r}\text { Definitely will } \\
\text { participate }\end{array}$} & \multicolumn{2}{|c|}{$\begin{array}{r}\text { Participants with } \\
\text { positive responses } \\
\text { (options 3-4) }\end{array}$} \\
\hline $\mathbf{n}$ & $\%$ & $\mathbf{n}$ & $\%$ & n & $\%$ & $\mathbf{n}$ & $\%$ & $n$ & $\%$ \\
\hline 102 & 11.50 & 294 & 33.00 & 433 & 48.80 & 59 & 6.60 & 492 & 55.28 \\
\hline
\end{tabular}

Table 8: Correlation coefficients among the subscales.

\begin{tabular}{lrrr}
\hline Variable & $\mathbf{1}$ & $\mathbf{2}$ & $\mathbf{3}$ \\
\hline 1. Program Quality (8 items) & - & - & - \\
2. Quality of Instructor (10 items) & $0.70^{\mathrm{a}}$ & - & - \\
3. Program Effectiveness (21 items) & $0.76^{\mathrm{a}}$ & $0.55^{\mathrm{a}}$ & - \\
4. Total Effectiveness (39 items) & $0.89^{\mathrm{a}}$ & $0.77^{\mathrm{a}}$ & $0.95^{\mathrm{a}}$ \\
\hline
\end{tabular}

${ }^{\mathrm{a} p}<0.01$
Table 9: Multiple regression analyses predicting program effectiveness.

\begin{tabular}{llllll}
\hline & \multicolumn{2}{l}{ Predictors } & \multicolumn{2}{l}{ Model } \\
\cline { 2 - 4 } & $\begin{array}{c}\text { 1. Program } \\
\text { quality }\end{array}$ & $\begin{array}{r}\text { 2. Quality of } \\
\text { instructor }\end{array}$ & \\
\hline Program effectiveness & $\beta^{\mathrm{a}}$ & $\beta^{\mathrm{a}}$ & $\mathrm{R}$ & $\mathrm{R}_{2}$ \\
& $0.74^{\mathrm{b}}$ & $0.04^{\mathrm{c}}$ & 0.76 & 0.58 \\
\hline
\end{tabular}

aStandardized coefficients, ${ }^{b} p<0.01$, ${ }^{\text {cSig. }}=0.227$. 
PE. Table 9 shows that only PQ can significantly predict $(\beta=0.74 ; p<0.00)$ PE, while QI had no significant prediction ( $\beta=0.04$; non-significant) towards PE. Therefore, only Hypothesis 2a was supported.

\section{Research question 5: prediction of overall satisfaction by perceived program and instructor attributes and perceived benefits}

Results of the multiple regression analyses (Table 10) showed that all factors had significant effects on the overall satisfaction toward the program. Higher level of perceived PQ $(\beta=0.50 ; p<0.00)$, QI $(\beta=0.06 ; p<0.05)$ and PE $(\beta=0.36 ; p<0.00)$ predicted higher overall satisfaction toward the program. The model explained $73 \%$ of the variance toward the prediction of students' overall satisfaction. Hypothesis 3 was supported.

\section{Discussion}

In this study, a 48-item scale was used to assess students' subjective perceptions of the program, instructors and effectiveness of the program. Several observations can be highlighted from the present findings. First, findings showed that the SOES possesses good psychometric properties. Factor analyses showed that the SOES has three major components - PQ, QI and PE, explaining 68.36\% of the variance. Reliability analyses showed that the total scale and subscales based on PQ, QI and PE possessed good internal consistency. Besides, results of correlation coefficients showed that these three factors are internally correlated. The findings basically replicated our previous findings of the psychometric properties of the SOES [10]. It further reinforces the claim that SOES is a valid and reliable tool to examine the subjective learning outcome of "Tomorrow's Leaders" $[6,9,10]$. As there are few validated measures of subjective outcome evaluation in different Chinese contexts $[9,10]$, this study contributes to the Chinese scientific literature.

Table 10: Multiple regression analyses predicting overall satisfaction.

\begin{tabular}{lllllll}
\hline & \multicolumn{2}{l}{ Predictors } & \multicolumn{3}{l}{ Model } \\
\cline { 2 - 5 } & $\begin{array}{l}\text { Program } \\
\text { quality }\end{array}$ & $\begin{array}{l}\text { Quality of } \\
\text { instructor }\end{array}$ & Program & & \\
\hline Overall satisfaction & $\beta^{\mathrm{a}}$ & $\beta^{\mathrm{a}}$ & $\beta^{\mathrm{a}}$ & $\mathrm{R}$ & $\mathrm{R}_{2}$ \\
& $0.50^{\mathrm{b}}$ & $0.06^{\mathrm{c}}$ & $0.36^{\mathrm{b}}$ & 0.85 & 0.73 \\
\hline
\end{tabular}

${ }^{\text {aS }}$ Standardized coefficients, ${ }^{b} p<0.01,{ }^{c} p<0.05$.
Secondly, descriptive analyses of the positive percentage of the 44 closed question items showed some interesting findings. Most of the students enjoyed experiential learning (i.e. were fully engaged in class discussion, applied concepts and theories to life examples), and they appreciated the opportunity to reflect on their past, present and future life. These findings supported the objective outcome of the course, which attempted to help students develop their intrapersonal and interpersonal competencies in the context of classroom learning [5]. However, it is noteworthy that some students indicated that they would not take similar subjects again in future. It would be interesting to explore the reasons behind. Besides, it would be important to understand the origin of the negative responses.

Thirdly, the hypotheses of the study were generally supported. Correlation analyses showed that PQ, QI and PE were highly related to the total effectiveness of the program. To further demonstrate the positive relationship, multiple regression analyses showed that PQ, QI and PE could predict overall satisfaction by explaining $73 \%$ of the variance. These findings are generally consistent with the findings reported previously and they were also consistent with the hypotheses of the study. Theoretically speaking, as there are few models on the determinants of subjective outcomes in the Chinese context, this is a significant contribution to the literature.

There are several strengths of this study. First, a relatively large sample size $(n=890)$ was used which could enhance generalizability of the research findings to other student populations. Second, as instructors encouraged the students to use reflective thinking and the identities of the students were anonymous, this might help the students to respond to the questionnaire in a non-threatening manner. Third, as there are few Chinese studies examining the determinants of subjective outcome evaluation in Chinese clients, the study is a welcome addition to the literature. Fourth, as there are few credit-bearing subjects attempting to promote intrapersonal and interpersonal competencies in university students and there are few related evaluation studies in the field, this is a valuable addition to the literature [12].

Nevertheless, there are some areas of improvement in this study. First, it is necessary to evaluate the overall learning benefits of the students in "Tomorrow's Leaders" by comparing the subjective outcomes with results collected from multiple evaluation approaches, such as objective outcome evaluation, process evaluation, focus groups and analysis of their reflective journals. To evaluate the effectiveness of the course "Tomorrow's Leaders" and how the course is connected with personal growth 
of university students, three more questions should be addressed: (a) Have there been any positive changes in the students who took this course (which could presumably be answered by objective outcome evaluation, reflective journals)? (b) What happened during the program implementation process (which could presumably be answered by process evaluation)? (c) What are the subjective experiences of the program instructors (e.g. qualitative evaluation)? Secondly, as alternative responses (i.e. a few negative written comments) were noted, it would be helpful to conduct further studies to understand those responses. Despite these limitations, the present study provides strong support for the effectiveness of "Tomorrow's Leaders" as a newly-established course to promote holistic youth development in Hong Kong. The present findings are generally consistent with the evaluation findings reported previously [11, 13-18].

The findings also emphasize the need to develop holistic education for university students worldwide. For the knowledge on adolescent development, this study provides strong support that we should continue to support the transitions from adolescence to adulthood through the implementation of life education programs. The students can get benefits from the leadership subject through learning the theories and doing self-reflection on intrapersonal and interpersonal development. To provide further benefits for their career planning, research on the personal competencies required in the job market should be meaningful to reinforce the curriculum support for their holistic development. In view of the growing developmental and mental health issues in university students in the global context, the developed subject and the related evaluation findings are important.

For the curriculum design, through experiential learning and teacher-student interactions (i.e. case study, role play, and group presentation of real life examples), students can understand and apply theories of leadership and intrapersonal development to their life. The utilization of appropriate self-disclosure, self-reflection and connecting concepts and theories to life experience can help students develop a holistic set of life skills, including critical thinking, problem solving, effective communication and ethical leadership. Actually, these curriculum design strategies can also be used in other subjects.

For the teaching approach, instructor and tutor are working together to assist students in their personal reflection and exploration of a healthy and positive identity. They are not just teaching skills, but providing care and companionship to students who go through the transformations of adolescence to adulthood. It may be helpful for the educators to change their mindset when engaging adolescents in the university setting - we do not simply teach them to receive orders, but we cultivate them to develop self-leadership skills to become a responsible global citizen. For young people transit from secondary schools to universities, they need more care and attention so that the transition can be a smooth one.

Acknowledgments: The preparation for this paper and the subject “Tomorrow's Leaders" were financially supported by The Hong Kong Polytechnic University.

\section{References}

1. Shek DT, Cheung BP. Developmental issues in university students in Hong Kong. Int J Adolesc Med Health 2013; 25:345-51.

2. Shek DT, Wong KK. Do adolescent developmental issues disappear overnight? Reflections about holistic development in university students. ScientificWorldJ 2011;11:353-61.

3. Shek DT, Ma HK, Sun RC. A brief overview of adolescent developmental problems in Hong Kong. ScientificWorldJ 2011;11:2243-56.

4. Hunt J, Eisenberg D. Mental health problems and helpseeking behavior among college students. J Adolesc Health 2010;46:3-10.

5. Shek DT, Sun RC, Chui YH, Lit SW, Yuen WW, Chung YY, et al. Development and evaluation of a positive youth development course for university students in Hong Kong. ScientificWorldJ 2012;2012:263731.

6. Shek DT, Sun RC. Promoting leadership and intrapersonal competence in university students: what can we learn from Hong Kong? Int J Disabil Hum Dev 2012;11:221-8.

7. Crosby DA. The most important course in the university. J Coll Character 2007;9:1-10.

8. Dalton J, Crosby P. The neglected inner lives of college students. J Coll Character 2006;8:1-9.

9. Shek DT, Sun RC. Post-course subjective outcome evaluation of a course promoting leadership and intrapersonal development in university students in Hong Kong. Int J Disabil Hum Dev 2013;12:193-201.

10. Shek DT, Yu L. Post-course subjective outcome evaluation of a subject on leadership and intrapersonal development for university students in Hong Kong. Int J Disabil Hum Dev 2014;13:457-64.

11. Shek DT, Sun RC. Promoting psychosocial competencies in university students: evaluation based on a one group pretestposttest design. Int J Disabil Hum Dev 2012;11:229-34.

12. Shek DT. Nurturing holistic development of university students in Hong Kong: where are we and where should we go? ScientificWorldJ 2010;10:563-75.

13. Shek DT, Sun RC. Process evaluation of a positive youth development course in a university setting in Hong Kong. Int J Disabil Hum Dev 2012;11:235-41.

14. Shek DT, Sun RC. Qualitative evaluation of a positive youth development course in a university setting in Hong Kong. Int J Disabil Hum Dev 2012;11:243-8. 
15. Shek DT, Sun RC. Focus group evaluation of a positive youth development course in a university in Hong Kong. Int J Disabil Hum Dev 2012;11:249-54.

16. Shek DT. Post-lecture evaluation of a positive youth development subject for university students in Hong Kong. ScientificWorldJ 2012;2012:934679.
17. Shek DT. Reflections of Chinese students on a university subject on leadership and intrapersonal development. Int J Disabil Hum Dev 2013;12:213-9.

18. Shek DT. Promotion of holistic development in university students: a credit-bearing subject on leadership and intrapersonal development. Best Pract Ment Health 2013;9:47-61. 